
\title{
R Reserach S Surare \\ BMC Nursing Tittle Meal Taking Behavior of Nurses in Government Health Clinics in Selangor and Its Associated Factors - A Cross Sectional Study
}

Huzaifah Hussin

Universiti Putra Malaysia

Titi Rahmawati Hamedon ( $\square$ rahmawati@upm.edu.my )

Universiti Putra Malaysia

\section{Research Article}

Keywords: Meal taking behavior, nurses, government health clinic

Posted Date: September 21st, 2021

DOl: https://doi.org/10.21203/rs.3.rs-712064/v1

License: (c) (1) This work is licensed under a Creative Commons Attribution 4.0 International License.

Read Full License 


\section{Abstract}

Introduction Meal taking behaviour MTB covers a broad definition, from food motive, pattern, dieting and diet related diseases. There are many factors that may affect MTB including social and environmental factors. Nurses were found to skip meals, take high calories food and fast foods. A good MTB is important for nurses 'health, maintaining good job performance and as role model to the public.

Materials and Methods: A cross-sectional study was conducted among randomly selected 178 staff nurses of public health clinics in Selangor who have fulfilled the inclusion and exclusion criteria Data was collected from September 2020 till March 2021 using pre-tested and validated self-administered questionnaire. Cronbach alpha were 0.78 for knowledge and 0.71 for MTB. Data was analysed using IBM Statistical Package for Social Science (SPSS) version 25.0 involving descriptive and inferential statistics. All ethical approval was obtained from ethical committees and written consent were received from all the respondents.

Result: The response rate was $97 \%$. Findings showed $42 \%$ of respondents had poor MTB, $47.1 \%$ had poor nutritional knowledge and $58.9 \%$ of nurses were overweight and obese. There was significant association between MTB with source of foods (breakfast and dinner) with $p=0.016$ and $p<0.001$ and eating companion during lunch $(p=0.003)$. Other factors, such as sociodemographic, working and employment factors were found to have not statistically significant association.

Conclusion: MTB showed to be a problem among nurses at the study location with a $42.9 \%$ of them had poor MTB and half of them nurses have weight problem. We found that MTB is significantly associated with their food source and eating companion. Intervention should be taken to improve the MTB of nurses.

\section{Background}

World-wide, nurses constitute to the highest number of health care workers in most of the health care setting including primary health care (PHC). Thus, they are in a position to play an important role as a mediator in connecting the public to health care services due to their close relationship with the public [1]. In PHC facilities, they are expected to promote healthy lifestyle to the public in order to prevent noncommunicable diseases [1] such as coronary vascular diseases and metabolic diseases which has been shown to have strong association with dietary factors and known as diet related diseases [2]. However, studies have found that nurses are also fighting their own battle to practice a good MTB [3][4][5].

MTB covers an extensive aspect from type or motive of food being chosen by individual, its pattern, dieting, amount of food intake and the health problem that may arise due to improper eating [27]. There are many factors that may influence a person's MTB as it is the result of interaction between many factors such as biological, mental, emotional, social, and genetic [7]. Among adult, additional factors related to working environment have been found to play its roles in creating a person's MTB as they routinely spend a minimum of 8 hours a day at the workplace and this pass through most of their daily 
mealtimes [8][9]. Working environment is commonly associated with a poor MTB and nurses are not exempted even though they work in health care facilities, and they are expected to practice good MTB [10]. Nurses were found to skip their meals especially breakfast, less complying to daily nutrients and calories requirement and in favour of high calories and fat content food such as in fast foods [3][6].

A good MTB is important in keeping the health of nurses [10]. Studies done in many countries including Malaysia have shown that nurses are facing weight problems as 25 to $50 \%$ of them have body mass index of more than $25 \mathrm{~kg} / \mathrm{m} 2$ [5][6][13][14]. Chronic diseases such as hypertension, diabetes and hyperlipidaemia also have becoming medical problems among nurses [3][4][6]. This situation is not in favour to the nurses as they need to be healthy to be a role model to the public. Practising good MTB is not only for preventing diet related diseases but is also crucial in ensuring nurses' performance at their workplace. Nurses who have good health can provide good service to the public [10]. This is because an employee who has been practising healthy diet will have better job performance and less frequency from taking medical leave [11]. Absenteeism among nurses not only affect the nurses' performance but may lead to the discontinuity in patient's care [12]. It also becomes an additional stress to other remaining colleagues as there will be increasing workload left by affected nurses [12].

In Malaysia, study conducted among nurses found them to be not practising good MTB. Given the frequency and regularities of taking their meals in a day, nurses tend to skip at least one meal and attributed it to their busy schedule and work demand [5]. Most of nurses did not strictly apply their knowledge on the correct food pyramid when taking their meals and majority of them were taking outside foods (shop bought foods) which is high in calories and fat. Their MTB were also affected by stress in view of the amount of the food taken [6]

The percentage of overweight and obese staff nurses in Malaysia have shown a worrying trend as reflected in studies conducted in Malaysia, which found $36-50 \%$ of the nurses had BMI more than $25 \mathrm{~kg} / \mathrm{m}^{2}[5,6]$. Previous study had also found that nurses in Malaysia had chronic diseases such as hypercholesterolaemia and hypertension [6]. This situation is not in favour of staff nurses' credibility in delivering health education on the public's perception [14]. Thus, it will affect the successfulness of their health programs due to lack of public's confident towards overweight or obese staff nurses [14]. Therefore, this study explored on the factors associated with MTB among nurses in health clinics. This study was conducted in Selangor as it received the highest number or patient per day in health clinic.

\section{Methods}

\section{Aim}

This study aimed to identify factors associated with meal taking behavior among nurses working in health clinics.

\section{Study design and Setting}


This was a cross sectional study, conducted in one of the districts in Selangor which consists of 10 health clinics. The health clinics are managed by District Health Office which provides health services to almost 230000 people and covered an area of $839.1 \mathrm{~km}^{2}$. It provides various kind of health services including pharmacy and health laboratory. The working hour of the clinics is from 8.00 a.m to 5 p.m. Two of the health clinics had longer operating times, from 8.00 a,m to 9.00 p.m done in two shifts (8a.m to 5.00 p.m and 12p.m to 9.00 p.m). There was a total of 312 nurses who work at the clinics and the number of nurses in each clinic varies depending on the type of the clinic and work burden. This study was carried out from September 2020 till March 2021.

\section{Participants}

The study population are staff nurses who work at health clinics. Staff nurse in this study was defined as a nurse who have certificate, diploma or degree in nursing and hold position as community nurses, nurses, head of nurses and nurse supervisor. The inclusion criteria were Malaysian citizen and permanent staff working in health clinics. Those who were pregnant, breastfeeding, on leave (for maternity reason or for further study or post basic courses) during the study period were excluded from this study.

Respondents were stratified based on health clinics and the numbers of nurses for each clinic were determined using proportionate sampling. A total of 178 respondents who fulfilled the selection criteria were selected by computer generated simple random sampling.

\section{Instrument}

This study used a self-administrated questionnaire adapted from the Malaysian Adult Nutrition survey as part of the National Health and Morbidity survey [15]. The questionnaire had three sections. Section A contains socio-demographic, employment factors and workplace factors (availability of pantry and cafeteria). There were 20 questions on MTB of the respondents during their working days in Section B, which was divided into meal pattern and meal format. In the section on meal pattern, respondents were asked on; days they took their breakfast, lunch, dinner, snacking and late-night heavy eating and in the section of meal format; serving and frequency they took vegetable, fruit, carbohydrate, protein, fast food, milk and dairy product and plain water were asked. Also in section $B$, the respondents were asked on the place and companion when they were taking their meals.

The MTB score was calculated by totalling up the score of all these 20 questionnaires. One score was given for each of the meal pattern question. The meal format was scored based on the median of the frequency and days of taking different type of foods, dairy products, and water. These total scores were then divided into good or poor MTB based on the median score as it was not normally distributed. Section C consisted of 55 questions on knowledge of MTB which was adapted from the Revised - General Nutritional Knowledge Questionnaire [28]. The level of knowledge was determined based on median score. The questionnaire was pre-tested on 40 nurses who were not part of the study participants. Pretesting results showed he Cronbach Alpha was 0.781 for knowledge and 0.712 for practice.

The height of study participants was measured in standing position, using mobile SECA stadiometer and the weight was measured to the nearest $0.1 \mathrm{~kg}$ with light clothing and empty pockets and without shoes 
using SECA weighing scale. Then, the BMI was calculated and classified based on the World Health Organization classification [29]. The BMI was classified into 4 categories: underweight $\left(<18.50 \mathrm{~kg} / \mathrm{m}^{2}\right)$, normal $\left(18.50-24.99 \mathrm{~kg} / \mathrm{m}^{2}\right)$, overweight $\left(25.00-29.99 \mathrm{~kg} / \mathrm{m}^{2}\right)$, obese $\left(>30.00 \mathrm{~kg} / \mathrm{m}^{2}\right)$,

\section{Data Collection}

All nurses that were selected based on the inclusion and exclusion criteria and random sampling were informed by the person in charge. The person in charge would be a nurse or head of a nurse appointed by a Family Medicine Specialist of each clinic. Each participant received a file that contains the consent form and a set of questionnaires. They were given time to go through the Participant Information Sheet that describes the study. Only those who consented were included in the study.

The data collection only started in July 2020 due to the Movement Control Order that began on 18 March 2020. In the session, the participants were given an explanation and were briefed about the study and they were encouraged to participate. Only nurses who were willing to participate and consented were included in the study. The questionnaire was distributed, and the nurses were expected to fill up the questionnaire within the time frame and the questionnaire was collected on the same day. The weight and height of the participants were recorded, and blood pressure was measured by the trained person in charge of the clinic. To prevent missing data, each questionnaire that was returned to the researcher was checked and any incomplete section will be returned to the participants.

\section{Data Analysis}

Data were analysed using the Statistical Analysis of Social Sciences System (SPSS) Version 25. A descriptive statistical analysis was presented using frequencies, percentage median and interquartile range regarding the MTB level and its associated factors. Chi square test was used to determine statistical associations between two categorical variables with meal taking behaviour. All hypotheses' testing were done as two sided and the level of significance a was set at 0.05 .

\section{Ethic and Consent to Participant}

The ethical approval to do this study was obtained from two committees. First, the Medical Research and Ethics Committee (MREC) of Ministry of Health (MOH) as this study was conducted in government health clinics and second from Ethics Committee for Research Involving Human Subjects Universiti Putra Malaysia or Jawatankuasa Etika Universiti untuk Penyelidikan Melibatkan Manusia (JKEUPM). Written informed consents were obtained from the respondents prior to data collection. All data and information of the study were kept and handled in a confidential manner which follow the usual laws and/or regulations.

All methods and procedure carried out during the study were performed in accordance with the relevant guidelines and regulations.

\section{Results}


A total of 178 questionnaires were distributed to the respondents who had been selected by a random sampling, and 170 respondents completed the questionnaire. The response rate for the study was $95.5 \%$.

Table 1 shows the sociodemographic distribution of respondents in this study. All the respondents were female, aged between 24-year-old to 57-year-old. Majority of them are Malay, Muslim, hold a nursing diploma as their highest education level. The household income was divided based on Malaysia's income classification which are B40 (income of less than Ringgit Malaysia (RM) 4850), M40 (income between RM4850 to RM10959) and T20 with a household income of more than RM10960. In this study majority of the nurses were in the B40 group category. 
Table 1

Sociodemographic distribution of Respondents $(\mathrm{N}=170)$

\begin{tabular}{|c|c|c|c|}
\hline Variables & Median (IQR) & Min -Max & $\begin{array}{l}\text { Frequency (n), } \\
\text { Percentage (\%) }\end{array}$ \\
\hline Age (year) & $35.5(10)$ & 24,57 & \\
\hline$<30$ & & & $26(15.3)$ \\
\hline $30-39$ & & & $89(52.3)$ \\
\hline$>40$ & & & $55(32.4)$ \\
\hline \multicolumn{4}{|l|}{ Ethnicity } \\
\hline Malay & & & $161(94.7)$ \\
\hline Indian & & & $4(2.4)$ \\
\hline Others & & & $5(2.9)$ \\
\hline \multicolumn{4}{|l|}{ Religion } \\
\hline Muslim & & & $163(95.9)$ \\
\hline Non-Muslim & & & $7(4.1)$ \\
\hline \multicolumn{4}{|l|}{ Marital status } \\
\hline Single & & & $6(3.5)$ \\
\hline Married & & & $157(92.4)$ \\
\hline Other & & & $7(4.1)$ \\
\hline Education level & & & $101(59.4)$ \\
\hline Diploma & & & $7(4.1)$ \\
\hline Degree & & & $62(36.5)$ \\
\hline \multicolumn{4}{|l|}{ Other } \\
\hline Household Income (RM) & $5000(3000)$ & 1500,15000 & \\
\hline$<4850$ & & & $56(32.9)$ \\
\hline $4850-10959$ & & & $109(64.2)$ \\
\hline$>10960$ & & & $5(2.9)$ \\
\hline
\end{tabular}

Most of the respondents who participated in this study were staff nurses (55.3\%), followed by community nurses (37.6\%). The remaining participants were head of nurses (sister), nurse supervisor (matron) and 'others', which include those who hold position as 'Khas Untuk Penanggung(KUP), a Bahasa Malaysia 
term which means a work position created especially for that particular staff only. There are equal numbers of respondents who had been in services for less than 10 years and between 10-to-20-year duration (71). There were two clinics which were appointed to carry out shift system starting July 2020 and that contributed to $31 \%$ of respondents in this study. The employment characteristics of the respondents shows in Table 2 below.

Table 2

Employment and Working Factors distribution of Respondent $(\mathrm{N}=170)$

\begin{tabular}{|c|c|c|c|}
\hline Variables & Median (IQR) & Min - Max & $\begin{array}{l}\text { Frequency (n), } \\
\text { Percentage (\%) }\end{array}$ \\
\hline Working duration (year) & $11(9)$ & 1,30 & \\
\hline$<10$ & & & $71(41.8)$ \\
\hline $10-19$ & & & $71(41.8)$ \\
\hline$>20$ & & & $28(16.4)$ \\
\hline \multicolumn{4}{|l|}{ Job title } \\
\hline Community Nurse & & & $64(37.6)$ \\
\hline Staff Nurse & & & $94(55.3)$ \\
\hline Head of Nurse & & & $8(4.7)$ \\
\hline Nurse Supervisor & & & $1(0.6)$ \\
\hline Other & & & $3(1.8)$ \\
\hline \multicolumn{4}{|l|}{ Working hour } \\
\hline Working in Shift & & & $52(30.6)$ \\
\hline Office hour & & & $118(69.4)$ \\
\hline Working time per week (hours) & $45(3.0)$ & 35,72 & \\
\hline$<45$ & & & $30(17.6)$ \\
\hline$>45$ & & & $140(82.4)$ \\
\hline \multicolumn{4}{|l|}{ Present of Pantry } \\
\hline Yes & & & $131(77.1)$ \\
\hline No & & & $39(22.9)$ \\
\hline \multicolumn{4}{|l|}{ Present of cafeteria } \\
\hline Yes & & & $34(20.0)$ \\
\hline No & & & $139(80.0)$ \\
\hline
\end{tabular}


The percentage of respondents who had either good or poor score of nutritional knowledge were almost equal as shown in Table 3. Only 38.2\% of the nurses had ideal body mass index while the remaining are either underweight $(2.9 \%)$ or had body mass index more than $25 \mathrm{~kg} / \mathrm{m}^{2}$.

Table 3

Personal Factors distribution of Respondent $(\mathrm{N}=170)$

\begin{tabular}{|llll|}
\hline Variables & Median (IQR) & Min -Max & $\begin{array}{l}\text { Frequency (n), } \\
\text { Percentage (\%) }\end{array}$ \\
\hline Nutritional Knowledge & $40(8)$ & 14,49 & \\
Good & & $90(52.9)$ \\
\hline Poor & & $80(47.1)$ \\
\hline Body mass index & $26.1(7.3)$ & $14.9,41.7$ & \\
\hline Underweight & & $5(2.9)$ \\
\hline Ideal & & $65(38.2)$ \\
\hline Overweight & & $54(31.8)$ \\
\hline Obese & & $46(27.1)$ \\
\hline Blood pressure & & \\
\hline Normotensive & & $160(94.1)$ \\
\hline Hypertensive & & $10(5.9)$ \\
\hline
\end{tabular}

Table 4 shows the environment or contextual factors that may affect MTB of the respondents. Respondent were asked on two items of each meal (breakfast, lunch and dinner) which were (1) source of the meal and (2) companion when they have their meals. The results are shown in Table 4. 
Table 4

Environment Factors distribution of Respondent $(\mathrm{N}=170)$

\begin{tabular}{|c|c|c|}
\hline Variables & Median (IQR) Min -Max & $\begin{array}{l}\text { Frequency (n), } \\
\text { Percentage (\%) }\end{array}$ \\
\hline \multicolumn{3}{|l|}{ Source of Breakfast } \\
\hline Home & & $69(40.6)$ \\
\hline Restaurant \& other & & $101(59.4)$ \\
\hline \multicolumn{3}{|c|}{ Companion during breakfast } \\
\hline Alone & & $71(41.8)$ \\
\hline Family members & & $19(11.2)$ \\
\hline Friend & & $80(48.0)$ \\
\hline \multicolumn{3}{|l|}{ Source of Lunch } \\
\hline Home & & $40(23.5)$ \\
\hline Restaurant & & $130(76.5)$ \\
\hline \multicolumn{3}{|c|}{ Companion during Lunch } \\
\hline Alone & & $23(13.5)$ \\
\hline Family members & & $14(8.2)$ \\
\hline Friends & & $133(78.2)$ \\
\hline \multicolumn{3}{|l|}{ Source of dinner } \\
\hline Home & & $141(82.9)$ \\
\hline Restaurant & & $29(17.1)$ \\
\hline \multicolumn{3}{|c|}{ Companion during dinner } \\
\hline Alone & & $10(5.9)$ \\
\hline Friends & & $160(94.1)$ \\
\hline
\end{tabular}

The MTB scores were calculated based on 20 questions. The respondents score ranged between 3 to full mark of 20. The MTB score was categorised based on the median cut off point score, to either good or poor category. A total of $42.9 \%$ of the respondents had poor MTB score and the remaining $57.1 \%$ had good score. The result is shown in Table 5. 


\begin{tabular}{|c|c|c|c|}
\hline Variables & Median (IQR) & Min -Max & $\begin{array}{l}\text { Frequency (n), } \\
\text { Percentage (\%) }\end{array}$ \\
\hline Meal taking behaviour & $13(4.25)$ & 3,20 & \\
\hline Good & & & $97(57.1)$ \\
\hline Poor & & & $73(42.9)$ \\
\hline \multicolumn{4}{|l|}{ Meal Pattern } \\
\hline \multicolumn{4}{|l|}{ Skipped Breakfast } \\
\hline Yes & & & $68(40.0)$ \\
\hline No & & & $102(60.0)$ \\
\hline \multicolumn{4}{|l|}{ Skipped Lunch } \\
\hline Yes & & & $25(14.7)$ \\
\hline No & & & $145(85.3)$ \\
\hline \multicolumn{4}{|l|}{ Skipped Dinner } \\
\hline Yes & & & $76(44.7)$ \\
\hline No & & & $94(55.3)$ \\
\hline \multicolumn{4}{|l|}{ Snacking } \\
\hline Yes & & & $153(90.0)$ \\
\hline No & & & $17(10.0)$ \\
\hline \multicolumn{4}{|c|}{ Eat heavy meals at midnight } \\
\hline Yes & & & $103(60.6)$ \\
\hline No & & & $67(39.4)$ \\
\hline \multicolumn{4}{|c|}{ Frequency of eating fruit per week } \\
\hline$<3$ & & & $64(37.6)$ \\
\hline$>3$ & & & $106(62.4)$ \\
\hline \multicolumn{4}{|c|}{ Frequency of eating vegetables per week } \\
\hline$<4$ & & & $59(34.7)$ \\
\hline$>4$ & & & $111(65.3)$ \\
\hline
\end{tabular}


Variables

$<5$

$>5$

Frequency of taking meat, fish, and poultry per week

$<5$

$>5$

Frequency of taking milk and dairy products per week

$<3$

$>3$

Frequency of taking fast foods per week

$<3$

$>3$

Frequency of drinking plain water per day

$<5$

5

Meal Format

Serving snack per day

$<1$

$>1$

Fruit Serving per day

$<2$

$>2$

Vegetables serving per day

$<3$

$>3$

Rice, noodles, and flour-based foods serving per day

$<3$

$>3$
Median (IQR) Min-Max Frequency (n),

Percentage (\%)

$47(27.6)$

$123(72.4)$

$52(30.6)$

$118(69.4)$

78 (45.9)

$92(54.1)$

$131(77.1)$

39 (22.9)

15 (8.8)

155 (91.2)

87 (51.2)

83 (48.8)

48 (28.2)

$122(71.8)$

71 (41.8)

99 (58.2)

74 (43.5)

96 (56.5) 


\begin{tabular}{|c|c|c|}
\hline Variables & Median (IQR) & $\begin{array}{l}\text { Frequency (n), } \\
\text { Percentage (\%) }\end{array}$ \\
\hline \multicolumn{3}{|c|}{ Meat, fish and poultry servings per day } \\
\hline$<3$ & & $67(39.4)$ \\
\hline$>3$ & & 103(60.6) \\
\hline \multicolumn{3}{|c|}{ Milk and dairy products serving per day } \\
\hline$<2$ & & $79(46.5)$ \\
\hline$>2$ & & $91(53.5)$ \\
\hline \multicolumn{3}{|c|}{ Fast food serving per day } \\
\hline$<2$ & & $109(64.1)$ \\
\hline$>2$ & & $61(35.9)$ \\
\hline \multicolumn{3}{|c|}{ Water serving per day } \\
\hline$<8$ glasses & & $61(35.9)$ \\
\hline$>8$ glasses & & $109(64.1)$ \\
\hline
\end{tabular}

The statistical associations between sociodemographic factors, employment factors, workplace factors, and personal factors with meal taking behaviours had been found to be not significant on each of the variables with $P>0.05$. However, the source of breakfast $(P=0.016)$, companion during taking lunch $(P=$ $0.002)$ and the source of dinner $(P=0.001)$ were found to be significantly associated with meal taking behaviour. 
Table 6

Statistical association between environment factors and MTB $(N=170)$

\begin{tabular}{|c|c|c|c|c|c|}
\hline \multirow[t]{2}{*}{ Variables } & \multirow{2}{*}{$\begin{array}{l}\text { Poor MTB } \\
(n=73)\end{array}$} & \multirow{2}{*}{$\begin{array}{l}\text { Good MTB } \\
(n=97)\end{array}$} & \multicolumn{3}{|c|}{ Test statistic } \\
\hline & & & $X^{2}$ & df & p-value \\
\hline \multicolumn{6}{|l|}{ Source of breakfast } \\
\hline Home & $22(30.1)$ & $47(48.5)$ & 5.795 & 1 & $0.016 *$ \\
\hline Restaurant \& others & $51(69.9)$ & $50(57.6)$ & & & \\
\hline \multicolumn{6}{|c|}{ Companion during Lunch } \\
\hline Alone & $9(12.3)$ & $14(14.4)$ & 11.392 & 2 & $0.003^{*}$ \\
\hline Family members & $12(16.4)$ & $2(2.1)$ & & & \\
\hline Friends & $52(71.2)$ & $81(83.5)$ & & & \\
\hline \multicolumn{6}{|l|}{ Source of dinner } \\
\hline Home & $52(71.2)$ & $89(91.8)$ & 12.396 & 1 & $0.001 *$ \\
\hline Restaurant & $21(28.8)$ & $8(8.2)$ & & & \\
\hline
\end{tabular}

\section{Discussion}

Logically, nurses were thought to practice healthy lifestyle by having a good MTB. However, in this study $42.9 \%$ of the nurses were found to have poor MTB which reflected that they did not practice what they had learn throughout their services. This finding is almost the same in comparison to a study that was carried out by Muhammad et al. among nurses in Malaysia with almost similar sociodemographic distribution but working in hospital setting [16]. Muhammad et al. (2014) in their study found $53 \%$ of the nurses perceived that they had poor eating by taking meal not at regular time (47\%), skipping breakfast (49\%), less frequent snacking (60\%), favour in fried food (89\%) and did not drink water as per recommended (90\%) [16]. This pattern of MTB of the nurses is expected as they were working in rotating shift and at the busiest wards (medical and surgical) with a high turnover of patient.

In this study, we found that most of the respondents skipped their meal (breakfast lunch or dinner), and they were mostly likely to skip dinner (44.7\%) and breakfast (40\%) throughout their working day. This was coherent to the finding by Coomarasamy et al. (2014) in their study among 1086 staff nurses in Malaysia who attended International Nursing Day and Seminar in 2012. These nurses were working at various public or private institution. They found a total of $37.2 \%$ of the nurses skip at least one meal per day. This show that, skipping meal was not only a problem among nurses working in hospital but also at other setting as well. 
In a study conducted in India [17], they found that $40 \%$ of nurses skipped their lunch and other meals. These results contradict with our findings. However, our study was carried out in health clinic setting with a different workload and working hours which may be a factor to better compliant to lunch compared to hospital nurses with rotating shift [18]. The trend of skipping breakfast and dinner among respondents needs to be prevented as it may increase the risk for overweight and obesity $[18,19.20 .21]$.

Abnormal body weights have become a great concern among nurses in Malaysia. More than half of our respondents had body mass index more than $25 \mathrm{~kg} / \mathrm{m}^{2}$ and $27.1 \%$ of the respondents were obese. These figures were higher when compared to the findings of previous studies where $18 \%$ to $23.5 \%$ of the respondents were found to be obese $[5,6,21]$. However, in our study the association between abnormal body weight and MTB was not statistically significant association.

Our research showed that eating home cooked foods for breakfast and dinner have significant association with a good MTB. A large cohort study found that taking frequent home cook foods was associated with better quality meals in terms of higher vegetable and fruit_contents [23]. In addition to that, healthy fruit juice intake was found to be higher among those who take home cooked foods [24]. Those who prepared less home cooked foods have significant association with eating fast foods and quick service foods [24]. Fast food and quick service foods are usually having high salt amount which sometimes exceed the daily recommended amount even with one meal [25].

Having companies when taking lunch was found to influence MTB, as found in this study. A person's MTB would be changed with whom they took their meal which also known as 'modelling' in order to adapt with the social norm [26,27]. In modelling, someone's MTB was affected by adjusting of the amount of the food intake due to the appropriateness based on the occasion [27]. Even though many people do not acknowledge that eating companion would affect their MTB compared to the self- factors such as hunger or type of food, however, study found that social cues did affect someone's MTB as in social model [27].

\section{Conclusion}

In this study we found that only less than two third of nurses in health clinics practice good MTB and half of them nurses have abnormal body weights. We also found that MTB is significantly associated with their food source especially for breakfast and dinner_meals. Eating companion during lunch is also found to influence MTB at workplace.

\section{Abbreviations}

MTB Meal Taking Behaviour

\section{Declarations}




\section{Ethic approval and consent to participate}

The ethical approval to do this study was obtained from two committees. First, the Medical Research and Ethics Committee (MREC) of Ministry of Health $(\mathrm{MOH})$ as this study was conducted in government health clinics and second from Ethics Committee for Research Involving Human Subjects Universiti Putra Malaysia or Jawatankuasa Etika Universiti untuk Penyelidikan Melibatkan Manusia (JKEUPM). Informed consents were obtained from the respondents prior to data collection. All data and information of the study were kept and handled in a confidential manner which follow the usual laws and/or regulations.

\section{Consent for publication}

Not applicable

\section{Availability of data and materials}

The datasets used and or analysed during the current study are available from the corresponding author on reasonable request.

\section{Competing interests}

The authors declare that they have no competing interests

\section{Funding}

This is a self-funding study.

\section{Author's contributions}

$\mathrm{HH}$ performed conceptualization, methodology, investigation, formal analysis and interpretation of data, and original draft writing. TRH had made substantial contributions in conceptualization, validation, writing review and editing, supervision. All authors have read and approved the manuscript.

\section{Acknowledgements}

The authors would like to thank to all nurses who participating in this study for their co-operation despite the current COVID-19 situation in Malaysia, Ministry of Health for giving us the opportunity to carry out the study and for University Putra Malaysia for their continuous support. 


\section{References}

1. Butler SM, Diaz C. Nurses as intermediaries in the promotion of community health: Exploring their roles and challenges. Brooking Edu; 2017. (Updated 2017 September 22 cited on 12 April 2021] Available from: https://www.brookings.edu/research/nurses-as-intermediaries-in-the-promotion-ofcommunity-health/

2. Micha R, Peñalvo JL, Cudhea F, Imamura F, Rehm CD, Mozaffarian D. Association between dietary factors and mortality from heart disease, stroke, and Type 2 diabetes in the United States. JAMA.2017;317(9):912-924. doi:10.1001/jama.2017.0947.

3. Ahmad, W, Taggart F, Shafique MS, Muzafar Y, Abidi S, Ghani, et al. Diet, exercise and mentalwellbeing of healthcare professionals (doctors, dentists and nurses) in Pakistan. Peer J, 2015; 17 (3), e1250.

4. Hazmi TM., Alghamdi A. \& Abdul I. Eating habits among healthcare providers during working hours at National Guard Health Affairs - Riyadh, Saudi Arabia. International Journal of Medical Research \& Health Sciences. 2018; 7(9), 1-14.

5. Coomarasamy, JD, Wint NN, Neri DLE, Sukumaran S. Prevalence of obesity and daily lifestyles of the Registered Nurses in Malaysia. International Journal of Innovation and Applied Studies. 2014; 7(3). 1202-1208.

6. Mohd Ardzi,R, Shariff N, Omar NZ, Ramli N. \& Md Isa KA. Understanding of obesity among Registered Nurse. The Malaysian Journal of Nursing. 2014; 6 (1), 38-43.

7. Grimm ER. \& Steinle NI. Genetics of eating behaviour: established and emerging concepts. Nutritional Review.2011; 69 (1); 52-60.

8. Leung SL, Barber JA, Burger A \& Barn RD. Factors associated with healthy and unhealthy workplace eating behaviours in individuals with overweight/obesity with and without binge eating disorder. Obesity Science \& Practice. 2018; 109-118.

9. Charoenbut P, Klaewkla J, Srisorrachatr S, Arphrorn S. Workplace and individual factors which influence eating practice of Thai factory workers. Mal J Nutr, 2018 .24(3): 417-426.

10. Reed, D. Healthy eating for healthy nurses: nutrition basics to promote health for nurses and patients. Online Journal of Issues in Nursing. 2014; 19 (3), 7.

11. Merrill. R.M., Aldana, S.G., Pope, J.E., Anderson, D.R.,Coberley, C. R. \& Grossmeier, J.J. Self-rated job performance and absenteeism according to employee engagement, health behaviors and physical health. JOEM, 2013. 55, (1), 10-18.

12. Mbombi MO, Mothiba TM, Malema RN, Malatji M. The effects of absenteeism on nurses remaining on duty at a tertiary hospital of Limpopo province. Curationis. 2018;41(1):e1-e5. Published 2018 Nov 27. doi:10.4102/curationis.v41i1.1924

13. Hick M, McDermott LL, Rouhana N, Schmidt M., Seymour MW \& Sullivan T. Nurses' body size and public confidence in ability to provide health education. Journal of Nursing Scholarship. 2008; 40 (4), 349-354. 
14. Spaulding EM. Instilling diet and exercise confidence: influence of nurse body size. Student research project14.2014; Retrieved from htpp://scholars.unh.edu/student_research/ 14

15. Institute for Public Health (IPH). National Health and Morbidity Survey 2014: Malaysian Adult Nutrition Survey (MANS). Institute for Public Health, Ministry of Health, Malaysia (Vol. 2). 2014; Retrieved from, https://doi.org/10.1017/СВ09781107415324.004

16. Muhammad CN, Mohd HZ, Ibrahim UK \& Borhan N. Psychological factors affecting eating habits among nurses in general hospital. RN Journal (2014). Retrieved from https://rn-journal.com/journalof-nursing/psych-factors-affecting-eating-habits-among-nurses

17. Gupta S. Dietary practices and nutritional profile of female nurses from Government Hospitals in Delhi, India. Iran J Nurs Midwifery Res. 2017; 22(5): 348-353. doi:10.4103/ijnmr.IJNMR_167_16.

18. Gupta CC, Coates AM, Dorrian J, Banks S. The factors influencing the eating behaviour of shift workers: what, when, where and why. Ind Health. 2019; 57(4): 419-453. doi:10.2486/indhealth.20180147.

19. Watanabe Y, Saito I, Henmi I, Yoshimura K, Maruyama K, Yamauchi K, Matsuo T, Kato T, Tanigawa T, Kishida T, Asada Y. Skipping breakfast is correlated with obesity. J Rural Med. 2014; 9(2): 51-8. doi: 10.2185/jrm.2887. Epub 2014 Jun 17. PMID: 25648986; PMCID: PMC4310153.

20. 10.1016/j.orcp.2019.12.002.

21. Yamamoto R, Tomi R, Shinzawa M, Yoshimura R, Ozaki S, Nakanishi K, Ide S, Nagatomo I, Nishida M, Yamauchi-Takihara K, Kudo T, Moriyama T. Associations of skipping breakfast, lunch, and dinner with weight gain and overweight/obesity in university students: A Retrospective Cohort Study. Nutrients. 2021; 13(1): 271. https://doi.org/10.3390/nu13010271.

22. Kunyahamu, M. S.; Daud, A.; Jusoh, N. Obesity among health care workers: Which occupations are at higher risk of being obese? Int. J. Environ. Res. Public Health 2021, 18, 4381. https://doi.org/10.3390/ ijerph18084381.

23. Mills, S., Brown, H., Wrieden, W. et al. Frequency of eating home cooked meals and potential benefits for diet and health: cross-sectional analysis of a population-based cohort study. Int J Behav Nutr Phys Act 2017, 17; 14(1), 109. https://doi.org/10.1186/s12966-017-0567-y.

24. Monsivais P, Aggarwal A, Drewnowski A. Time spent on home food preparation and indicators of healthy eating. Am J Prev Med. 2014;47:796-802.

25. Jaworowska, A., Blackham, T., Stevenson, L., \& Davies, I. G. (2012). Determination of salt content in hot takeaway meals in the United Kingdom. Appetite, 59(2), 517-522. doi:10.1016/j.appet.2012.06.018.

26. Higgs, S., \& Thomas, J. (2016). Social influences on eating. Current Opinion in Behavioural Sciences, 9, 1-6. doi:10.1016/j.cobeha.2015.10.005.

27. L.R. Vartanian, N. Sokol, C.P. Herman, J. Policy Social models provide a norm of appropriate food intake PLOS ONE, 8 (2013), e7926, 10.1371/journal.pone.0079268.

28. Kliemann N, Wardle J, Johnson F, Croker H. Reliability and validity of a revised version of the General Nutrition Knowledge Questionnaire. Eur J Clin Nutr. 2016 Oct;70(10):1174-1180. doi: 
10.1038/ejcn.2016.87. Epub 2016 Jun 1. PMID: 27245211; PMCID: PMC5014128.

29. World Health Organization. Health topic "Body Mass Index" Cited on 1 June 2021; Retrieved from https://www.euro.who.int/en/health-topics/disease-prevention/nutrition/a-healthy-lifestyle/bodymass-index-bmi . 